\title{
Protocol
}

\section{Larval Thymectomy of Xenopus laevis}

\author{
Sara Mashoof, ${ }^{1}$ Breanna Breaux, ${ }^{1}$ and Michael F. Criscitiello ${ }^{1,2,3}$ \\ ${ }^{1}$ Comparative Immunogenetics Laboratory, Department of Veternary Pathobiology, College of Veterinary \\ Medicine and Biomedical Sciences, Texas A\&M University, College Station, Texas 77843; ${ }^{2}$ Department of \\ Microbial Pathogenesis and Immunology, College of Medicine, Texas A\&M Health Science Center, Texas A\&M \\ University, College Station, Texas 77843
}

In jawed vertebrates from sharks to mammals, the thymus is the primary (or central) lymphoid tissue where T cells develop and mature. The particular stromal cell types, cytokine environment, and tissue organization in the thymus are essential for $\mathrm{V}(\mathrm{D}) \mathrm{J}$ recombination, positive selection for major histocompatibility complex recognition, and negative selection against self-peptide recognition of most $\alpha \beta$ T cells. The thymectomy operation on Xenopus tadpole larva described here creates a T-cell-deficient model suitable for many immunology studies.

It is essential that you consult the appropriate Material Safety Data Sheets and your institution's Environmental Health and Safety Office for proper handling of equipment and hazardous materials used in this protocol.

RECIPES: Please see the end of this protocol for recipes indicated by $<R>$. Additional recipes can be found online at http://cshprotocols.cshlp.org/site/recipes.

Reagents

Carbenicillin

Human chorionic gonadotropin (hCG; $200 \mathrm{U} / \mathrm{mL}$ in amphibian phosphate-buffered saline

[PBS] $<\mathrm{R}>$ )

$\mathrm{NaCl}$, saturated aqueous solution

Tricaine methanesulfonate (MS222)

Xenopus laevis, males and females, breeding age

Equipment

Beakers, plastic

Cheesecloth

Dissection microscope

Metal plate stage, grounded

Microcautery device (e.g., an aphid Zapper, a device designed for stylectomy)

${ }^{3}$ Correspondence: mcriscitiello@cvm.tamu.edu

From the Xenopus collection, edited by Hazel L. Sive.

(C) 2018 Cold Spring Harbor Laboratory Press

Cite this protocol as Cold Spring Harb Protoc; doi:10.1101/pdb.prot099192 
S. Mashoof et al.

Our device delivers a VHF pulse of 10 msec-duration and a power of 10 watts to the target tissue via an abraded tungsten wire.

Needles, tungsten

Sharpen the tungsten needles by electrolysis (Brady 1965). The same Zapper instrument used for microcauterization can be used to fashion desired needle points by bobbing the wire tip up and down in a saturated sodium chloride solution.

Pipettes, plastic

Water aerator

\section{METHOD}

There are differing views as to the ideal developmental window for thymectomies to be performed. Although thymus visualization is more difficult, earlier thymectomies-e.g., from day 4 to day 7 post-spawn (Nieuwkoop and Faber stages 45-48 [Nieuwkoop and Faber 1994]) - are recommended. This is the period where the thymus is developing, but lymphoid lineage cells have not yet migrated to the thymus (Horton and Manning 1972; Arnall and Horton 1987). Past this time, $T$ cells can mature and escape into the periphery, resulting in incomplete $T$ cell ablation.

Spawning

Methods for spawning Xenopus laevis vary. We use hCG injections into the dorsal lymph sacs to induce amplexus.

1. Prime a male Xenopus with $40 \mathrm{U}$ and a female Xenopus with $20 \mathrm{U}$ of hCG. Leave in separate tanks overnight.

2. Administer an additional $250 \mathrm{U}$ of hCG to the female the following morning.

3. Four hours later, add the male and female to a shared tank containing spawning mops, nylon mesh, or marbles. Cover the tank to keep it dark and avoid disturbances.

Anesthesia

Individuals vary in susceptibility to MS222 toxicity. Overexposure to MS222 reduces the chance of tadpole recovery. Do not leave tadpoles in the MS222 bath for longer than $15 \mathrm{~min}$.

4. Dilute $30 \mathrm{mg}$ of MS222 in $100 \mathrm{~mL}$ of buffered vivarium system $\mathrm{H}_{2} \mathrm{O}$ in a plastic beaker.

5. Construct a tadpole "net" by looping a plastic pipette back on itself and covering it with a piece of cheesecloth. Secure the cheesecloth to the pipette with tape (Fig. 1D).

6. Using the net, capture a tadpole. Place it in the MS222 bath.

7. Monitor the tadpole for 1-3 min until it has stopped moving.

8. Retrieve the tadpole from the anesthesia using the net.

If it is still moving, return it to the MS222 bath.

Thymectomy

9. Wet a piece of cheesecloth with dechlorinated tank water. Place it on the dissection microscope stage. Position the cloth such that a section overlaps with the grounded metal plate stage, illuminating the cloth from below in the field of view.

10. Using the net, transfer the anesthetized tadpole to the stage cheesecloth so that the light shines through it. Position the tadpole on its ventral side with either the eyes or tail facing forward (Fig. 1F).

11. Locate the thymus using the microscope.

The thymus is located bilaterally caudal and medial to the eyes and lateral to the dark central nervous system (Fig. 2). Note that the thymus shown in Figure 2 is at a later stage of development where it is melanized and easily visualized; at the present stage, the thymus will not be melanized and will appear as a small, clear oval or circular sac (Fig. 1F). 

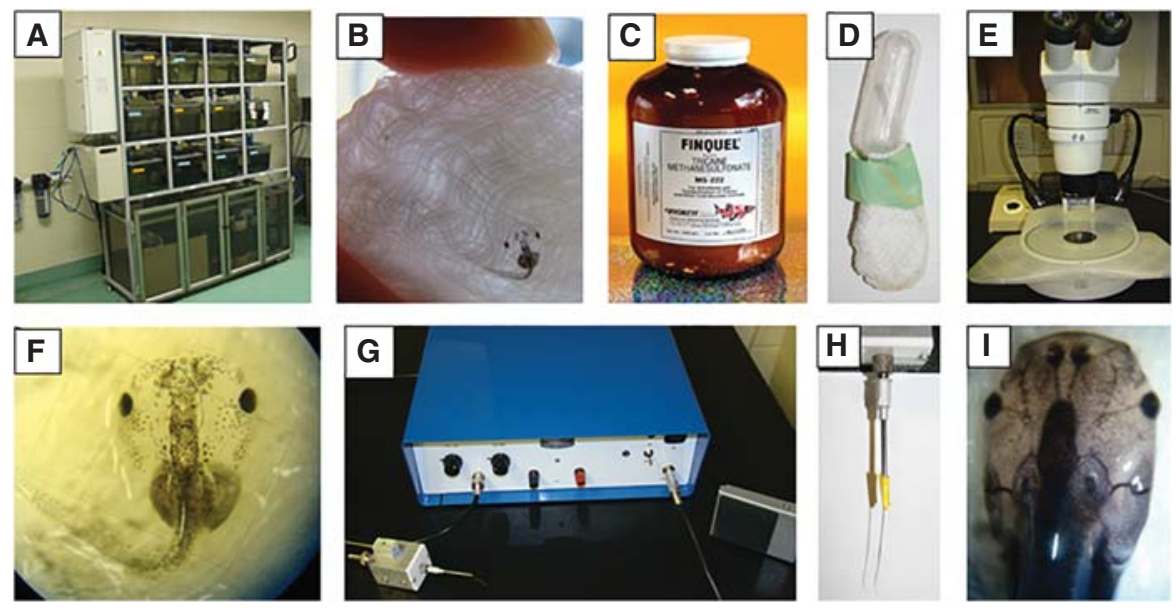

FIGURE 1. Procedural progression. (A) The recirculating system housing the frogs. (B) Xenopus tadpole at eight days of age. (C) MS222 used for tadpole anesthesia. $(D)$ Tadpole net formed from cheesecloth over bent transfer pipette. $(E)$ The dissection microscope. $(F)$ Same tadpole as shown in $(B)$, as viewed under the dissection microscope. $(G)$ The microcautery apparatus used for the Xenopus thymectomy. $(H)$ Close-up of tungsten needle. $(I)$ A fully thymectomized tadpole with no visible thymus.

12. Optionally, dab the surface of the tadpole covering the developing thymus with a small piece of tissue paper to dry the skin.

If thymectomizing later in the optimal window (e.g., day 7 post-spawn), using the dissection needle to rupture the skin and provide better exposure of the thymus before administering the electrical pulse can increase accuracy and improve efficiency of ablation.

13. Use the microcautery apparatus needle to burn the bilateral thymus organ away on one side of the tadpole:

i. While looking through the microscope, lower the needle until it is visible.

ii. Place the needle on the tadpole near the thymus.

iii. Press the foot pedal to administer an electrical pulse.

Ideally, the thymus should be burned with only one quick pulse on the thymic lobe (Fig. 1). If the thymus is still visible, a second pulse can be administered; however, this decreases the chance of survival and should be avoided when possible.

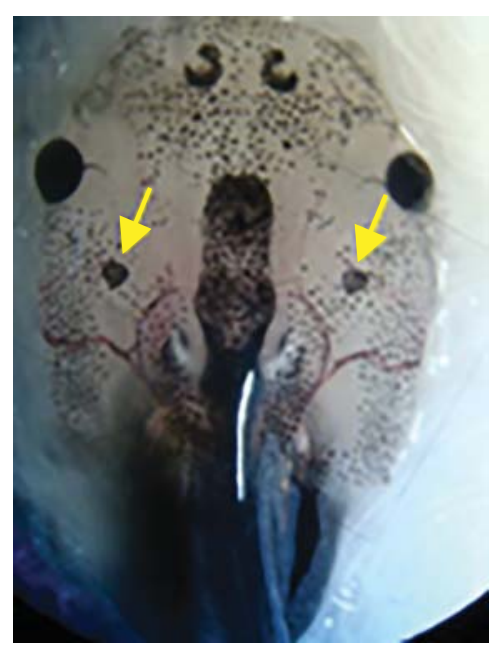

FIGURE 2. Localization of thymus. In Xenopus tadpole the thymus is located (yellow arrows) bilaterally caudal and medial to the eyes and lateral to the dark central nervous system. 
S. Mashoof et al.

14. Repeat Steps 13.i-13.iii on the other half of the bilateral organ on the other side of the animal. Rotating the cheesecloth allows use of one's dominant hand for both procedures, but takes precious time to reposition. With practice, both sides of the tadpole can be ablated with a single positioning.

\section{Recovery}

15. Immediately after thymic ablation use the net to transfer the tadpole to an ice bath. Cool the animal for $3 \mathrm{sec}$.

16. Transfer the tadpole to a plastic beaker of aerated regular tank water containing carbenicillin at a concentration of $80 \mathrm{mg} / \mathrm{L}$. Allow the tadpole to recover for $1 \mathrm{~h}$.

See Troubleshooting.

17. Transfer the tadpole to a designated tank in the primary recirculating Xenopus husbandry system.

18. Repeat Steps 4-17 with the remaining tadpoles.

Screen thymectomized tadpoles for regrowth of the thymus at 1 and 2 wk after the surgery (see Steps 1922). See Troubleshooting.

Screening

19. Dilute $30 \mathrm{mg}$ of MS222 in $100 \mathrm{~mL}$ of system $\mathrm{H}_{2} \mathrm{O}$ in a plastic beaker.

20. Wet a piece of cheesecloth with regular tank water. Place it on the dissection microscope stage.

21. Use the net to transfer a thymectomized tadpole into the MS222 bath. Remove the tadpole from the anesthesia after $30 \mathrm{sec}$.

Complete immobilization is not necessary for screening.

22. Transfer the tadpole onto the stage cheesecloth. Carefully inspect it through the microscope.

If a melanized thymus can be detected on either side of the tadpole (see, e.g., Fig. 2 versus Fig. 1I), the thymectomy was unsuccessful. Tadpoles with thymic regrowth should be euthanized by exposure to an overdosed bath of MS222 (>1000 mg/L) for at least $1 \mathrm{~h}$.

Problem (Step 16): The tadpole does not recover from anesthesia.

Solution: MS222 can be toxic at high doses or with slower processing times. Variable size and pharmacogenetics will cause some tadpoles not to recover in the aerated post-surgery tank. Lower levels of MS222 (e.g., $10 \mathrm{mg} / 100 \mathrm{~mL}$ [Rollins-Smith et al. 1996] or $20 \mu \mathrm{g} / \mathrm{mL}$ [Tochinai 1975]) have been used successfully and might increase survival.

Problem (Step 18): The tadpoles die in the days following the thymectomy.

Solution: This surgery can have a low survival rate because of the traumatic nature of the procedure. However, if you experience very low rates, several variables can be altered. The ice bath postthymectomy is optional: Although lowering the body temperature lowers the metabolic rate and can therefore increase survival, it comes at the cost of increased handling of the tadpole, which disrupts the outer mucous membrane. Similarly, some have performed the thymectomy procedure itself on a chilled agar plate. The use of antibiotics in the recovery tank is also optional, and could disrupt mutualistic bacterial skin and gastrointestinal flora.

The thymus is the primary lymphoid tissue for T cell development (Cooper et al. 1966; Criscitiello et al. 2010). Additionally, the frog undergoes class switch recombination of the immunoglobulin heavy chain locus in a translocon organization and somatic hypermutation driven by specialized 
follicular antigen presentation (Neely et al. 2018). The frog thymectomy model has been used for decades (Horton and Manning 1972) and is now an established model of adaptive immunity absent the effect of T cells in a metamorphosing tetrapod vertebrate (see, e.g., Sakuraoka and Tochinai 1993; Ono and Tochinai 1995; Kinney et al. 1996; Robert et al. 1997; Horton et al. 2003; Mashoof et al. 2013).

The relatively superficial position of the bilateral organ in developing anuran amphibians makes the frog thymectomy model straightforward. Alternatively, in the Northern leopard frog Rana pipiens, it can even be aspirated using a fine glass micropipette (Rollins-Smith and Cohen 1982). A late larval thymectomy model has also been used in Xenopus laevis to explore the persistence of larval T cells post-metamorphosis (Rollins-Smith et al. 1996).

RECIPE

Amphibian Phosphate-Buffered Saline (APBS)

Sodium chloride $(\mathrm{NaCl})$ $6.6 \mathrm{~g} / \mathrm{L}$

Sodium phosphate $\left(\mathrm{Na}_{2} \mathrm{HPO}_{2}\right)$

$1.15 \mathrm{~g} / \mathrm{L}$

Potassium phosphate $\left(\mathrm{KH}_{2} \mathrm{PO}_{4}\right)$

$0.2 \mathrm{~g} / \mathrm{L}$

Adjust $\mathrm{pH}$ to 7.7 with $10 \mathrm{~N} \mathrm{NaOH}$, and filter-sterilize through a $0.2-\mu \mathrm{m}$ filter. Store at room temperature for up to $6 \mathrm{mo}$.

\section{REFERENCES}

Arnall JC, Horton JD. 1987. In vivo studies on allotolerance perimetamorphically induced in control and thymectomized Xenopus. Іттиnology 62: 315-319.

Brady J. 1965. A simple technique for making very fine, durable dissecting needles by sharpening tungsten wire electrolytically. Bull World Health Organ 32: 143-144.

Cooper MD, Peterson RDA, South MA, Good RA. 1966. The functions of the thymus system and the bursa system in the chicken. J Exp Med 123: 75-102.

Criscitiello MF, Ohta Y, Saltis M, McKinney EC, Flajnik MF. 2010. Evolutionarily conserved TCR binding sites, identification of T cells in primary lymphoid tissues, and surprising trans-rearrangements in nurse shark. J Immunol 184: 6950-6960.

Horton JD, Manning MJ. 1972. Response to skin allografts in Xenopus laevis following thymectomy at early stages of lymphoid organ maturation. Transplantation 14: 141-154.

Horton TL, Stewart R, Cohen N, Rau L, Ritchie P, Watson MD, Robert J, Horton JD. 2003. Ontogeny of Xenopus NK cells in the absence of MHC class I antigens. Dev Comp Immunol 27: 715-726.

Kinney KS, Felten SY, Cohen N. 1996. Sympathetic innervation of the amphibian spleen: Developmental studies in Xenopus laevis. Dev Comp Immunol 20: 51-59.

Mashoof S, Goodroe A, Du CC, Eubanks JO, Jacobs N, Steiner JM, Tizard I, Suchodolski JS, Criscitiello MF. 2013. Ancient T-independence of mucosal $\operatorname{IgX/A}$ : Gut microbiota unaffected by larval thymectomy in Xenopus laevis. Mucosal Immunol 6: 358-368.
Neely HR, Guo J, Flowers EM, Criscitiello MF, Flajnik MF. 2018. “Doubleduty" conventional dendritic cells in the amphibian Xenopus as the prototype for antigen presentation to B cells. Eur J Immunol 48: 430-440.

Nieuwkoop PD, Faber J (eds.). 1994. Normal table of Xenopus laevis (Daudin): A systematical and chronological survey of the development from the fertilized egg till the end of metamorphosis. Garland Publishing, New York.

Ono M, Tochinai S. 1995. Demonstration of cells possessing tolerance-inducing activity in Xenopus laevis rendered tolerant perimetamorphically. Transplantation 60: 66-70.

Robert J, Guiet C, Cohen N, Du Pasquier L. 1997. Effects of thymectomy and tolerance induction on tumor immunity in adult Xenopus laevis. Int $J$ Cancer 70: 330-334.

Rollins-Smith LA, Cohen N. 1982. Effects of early larval thymectomy on mitogen responses in leopard frog (Rana pipiens) tadpoles. Dev Comp Immunol 6: 303-309.

Rollins-Smith LA, Needham DA, Davis AT, Blair PJ. 1996. Late thymectomy in Xenopus tadpoles reveals a population of $\mathrm{T}$ cells that persists through metamorphosis. Dev Comp Immunol 20: 165-174.

Sakuraoka J, Tochinai S. 1993. Demonstration of cells involved in rejection of tolerogenic grafts in tolerant Xenopus. Dev Comp Immunol 17: 439-447.

Tochinai S. 1975. Success of thymectomy from larval Xenopus at the earliest stage of its histogenesis. Zool Mag 84: 138-141. 


\section{Larval Thymectomy of Xenopus laevis}

Sara Mashoof, Breanna Breaux and Michael F. Criscitiello

Cold Spring Harb Protoc; doi: 10.1101/pdb.prot099192 originally published online May 16, 2018

\begin{tabular}{rc}
\hline $\begin{array}{r}\text { Email Alerting } \\
\text { Service }\end{array}$ & Receive free email alerts when new articles cite this article - click here. \\
\hline $\begin{array}{c}\text { Subject } \\
\text { Categories }\end{array}$ & $\begin{array}{c}\text { Browse articles on similar topics from Cold Spring Harbor Protocols. } \\
\text { Developmental Biology (728 articles) } \\
\text { Immunology, general (128 articles) } \\
\text { Xenopus (210 articles) }\end{array}$ \\
\hline
\end{tabular}

